\title{
Mullite whiskers prepared by molten salt method using Si powders
}

\author{
Wei WANG ${ }^{a,}$, Hongwei $\mathrm{LI}^{b}$, Yajie $\mathrm{GUO}^{b}$, Qiang $\mathrm{SUN}^{a}$, Chen $\mathrm{CHEN}^{a}$ \\ ${ }^{a}$ Department of Chemical Engineering, College of Environment Science and Engineering, Chang'an University, \\ Xi'an 710054, China \\ ${ }^{b}$ College of Materials Science and Engineering, Chang'an University, Xi'an 710061, China
}

Received: September 14, 2012; Revised: November 4, 2012; Accepted: November 12, 2012

(OThe Author(s) 2012. This article is published with open access at Springerlink.com

\begin{abstract}
Mullite whiskers were prepared from Si powders in molten $\mathrm{Al}_{2}\left(\mathrm{SO}_{4}\right)_{3}-\mathrm{Na}_{2} \mathrm{SO}_{4}$ mixture salts with different $\mathrm{Al} / \mathrm{Si}$ molar ratio $(R)$ of raw materials. The resulting mullite whiskers, had been investigated using X-ray diffraction (XRD), scanning electron microscopy (SEM), energy dispersive spectrometer (EDS) and infrared spectroscopy analysis (FT-IR). Mullite phase was obtained in molten salts when the temperature reached at $850{ }^{\circ} \mathrm{C}$. SEM and EDS results revealed that two kinds of microstructures were formed in the final product, Al-rich mullite pellets and clusters of tiny mullite crystals, and the content of Al-rich mullite pellets increased with the higher $\mathrm{Al} / \mathrm{Si}$ molar ratio $(R)$ adopted in raw materials. A new oxidation-dissolution mechanism was proposed to explain mullite whiskers growth. According to thermodynamic analysis, mullite phase might be spontaneously formed as the temperature reached the decomposition temperature of aluminum sulfate (1023 K).
\end{abstract}

Key words: chemical preparation; whiskers; mullite; infrared spectroscopy

\section{Introduction}

Mullite is an attractive potential engineering ceramic because it has high strength and high creep resistance at both low and high temperatures, a low thermal expansion coefficient and good chemical and thermal stability. Mullite whiskers have attracted attention as a possible reinforcement for high temperature structure materials. Various processing routes have been reported for the preparation of mullite whiskers such as sol-gel [1,2], high-energy ball milling process [3-5], internal crystallization method [6] and thermal decomposition of minerals [7]. However, these

* Corresponding author.

E-mail: wwchem@yahoo.cn conventional synthesis methods have apparent shortcomings that the reactive system needs providing higher crystallization temperature and longer crystallization time. As a new ceramic powder synthesis method, molten salt synthesis has been employed to synthesize ceramic powders because it decreases reaction temperature and gives powders of homogeneous morphology [8]. Mullite whiskers formation in molten salts system has been extensively studied [9-13]. But earlier studies focused on utilizing $\mathrm{SiO}_{2}$ as raw material, there was no report about the preparation of mullite whiskers from Si powders by molten salt synthesis.

In this paper, mullite whiskers were prepared in $\mathrm{Al}_{2}\left(\mathrm{SO}_{4}\right)_{3}-\mathrm{Na}_{2} \mathrm{SO}_{4}$ mixture molten salts using $\mathrm{Si}$ powders. The morphology of mullite whiskers prepared by firing mixture powders with different 
$\mathrm{Al} / \mathrm{Si}$ molar ratios $(R)$ were investigated, and the oxidation-dissolution mechanism was proposed to explain the reactive process.

\section{Experimental procedures}

As raw materials, aluminum sulfate hydrate $\left[\mathrm{Al}_{2}\left(\mathrm{SO}_{4}\right)_{3} \cdot 18 \mathrm{H}_{2} \mathrm{O}, \mathrm{AR}\right]$, sodium sulfate $\left[\mathrm{Na}_{2} \mathrm{SO}_{4}, \mathrm{AR}\right]$ and $\mathrm{Si}$ powders (AR) (Xi'an Chemical Reagent Factory) were used. The mean particle size of $\mathrm{Si}$ powders was $30 \mu \mathrm{m}$.

Aluminum sulfate hydrate was placed in a microwave oven and heated with high fire for $10 \mathrm{~min}$ to remove intra-molecular water. Aluminum sulfate and Si powders were weighed accurately according to the different $\mathrm{Al} / \mathrm{Si}$ molar ratio $(R)$. The weight of sodium sulfate was equal to the total weight of aluminum sulfate and Si powders. The mixture was grinded in a ceramic mortar for $30 \mathrm{~min}$, then heated to the sintering temperature for $1 \mathrm{~h}$ and cooled down to room temperature in air. The samples were washed with $95{ }^{\circ} \mathrm{C}$ water to remove the sulfate. Finally, white mullite powders were obtained after filtration, washing and drying. While the $\mathrm{Al} / \mathrm{Si}$ molar ratio $R$ was 3, two samples were obtained at different sintering temperature $850{ }^{\circ} \mathrm{C}$ and $900{ }^{\circ} \mathrm{C}$ with $1 \mathrm{~h}$ holding time, named as sample $\mathrm{S} 1\left(R=3,850{ }^{\circ} \mathrm{C}\right)$ and sample $\mathrm{S} 2$ $\left(R=3,900{ }^{\circ} \mathrm{C}\right)$. When the sintering temperature was constant $\left(900{ }^{\circ} \mathrm{C}\right)$, another three samples were got with different $\mathrm{Al} / \mathrm{Si}$ molar ratio $(R=3.5,4.5$ and 5.5$)$, named as $\mathrm{S} 3\left(R=3.5,900{ }^{\circ} \mathrm{C}\right), \mathrm{S} 4\left(R=4.5,900{ }^{\circ} \mathrm{C}\right)$ and $\mathrm{S} 5$ $\left(R=5.5,900{ }^{\circ} \mathrm{C}\right)$.

Crystalline phase and morphology of the samples were measured by X-ray diffractometer (XRD, D/MAX-RA) and scanning electronic microscope (SEM, S-2700) equipped with an energy dispersive spectrometer (EDS, INCA-350), respectively. Infrared spectroscopy (IR) studies were performed with infrared spectrometer (AVATAR 360 FT-IR, Nicolet) in the wavenumber range of $4000-400 \mathrm{~cm}^{-1}$.

\section{Results and discussion}

\section{1 $\mathrm{Na}_{2} \mathrm{SO}_{4}-\mathrm{Al}_{2}\left(\mathrm{SO}_{4}\right)_{3}$ phase diagram analysis}

The corresponding $\mathrm{Na}_{2} \mathrm{SO}_{4}-\mathrm{Al}_{2}\left(\mathrm{SO}_{4}\right)_{3}$ phase diagram is shown in Fig. 1 [14]. The phase diagram of the molten salts system consists of eight areas which correspond

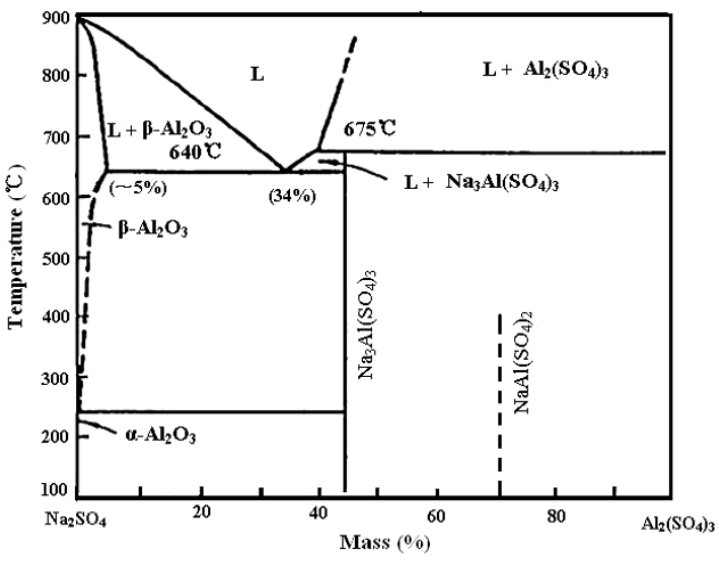

Fig. 1 Phase diagram of system $\mathrm{Na}_{2} \mathrm{SO}_{4}-\mathrm{Al}_{2}\left(\mathrm{SO}_{4}\right)_{3}$.

to different materials $\alpha-\mathrm{Al}_{2} \mathrm{O}_{3}, \beta-\mathrm{Al}_{2} \mathrm{O}_{3}, \mathrm{~L}+\beta-\mathrm{Al}_{2} \mathrm{O}_{3}, \mathrm{~L}$, $\mathrm{L}+\mathrm{Al}_{2}\left(\mathrm{SO}_{4}\right)_{3}, \quad \mathrm{NaAl}\left(\mathrm{SO}_{4}\right)_{2}, \quad \mathrm{Na}_{3} \mathrm{Al}\left(\mathrm{SO}_{4}\right)_{3} \quad$ and $\mathrm{L}+\mathrm{Na}_{3} \mathrm{Al}\left(\mathrm{SO}_{4}\right)_{3}$, respectively. Furthermore, it can be seen that the eutectic melt form at $640{ }^{\circ} \mathrm{C}$ in mixture molten salt system of $34 \%$ mass fraction aluminum sulfate. Aluminum sulfate and sodium sulfate could melt each other with any ratio when the temperature up to $900{ }^{\circ} \mathrm{C}$. Therefore, it is important and indispensable to investigate $\mathrm{Na}_{2} \mathrm{SO}_{4}-\mathrm{Al}_{2}\left(\mathrm{SO}_{4}\right)_{3}$ quantitative system at $900{ }^{\circ} \mathrm{C}$ for mullite whiskers synthesis.

\subsection{XRD analysis}

The XRD patterns of samples S1 and S2 are shown in Fig. 2. Mullite phase is the main composition of the product, and diffraction peaks of $\mathrm{Si}$ and $\gamma-\mathrm{Al}_{2} \mathrm{O}_{3}$ are also observed in the final samples, indicating that mullite phase form in molten salts as the temperature reached $850{ }^{\circ} \mathrm{C}$. Moreover, the content of $\mathrm{Si}$ in the product decreases with increasing the sintering

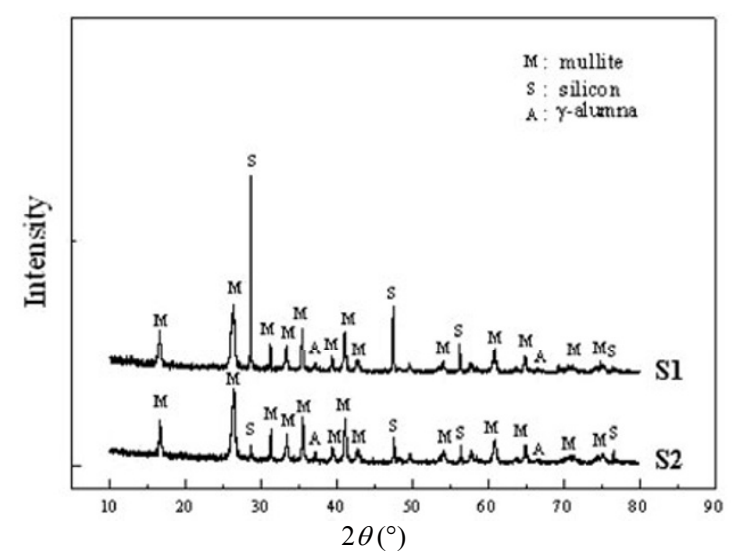

Fig. 2 X-ray diffraction pattern of samples $\mathrm{S} 1$ $\left(R=3,850{ }^{\circ} \mathrm{C}\right)$ and $\mathrm{S} 2\left(R=3,900{ }^{\circ} \mathrm{C}\right)$. 
temperature. Therefore, we selected higher temperature $\left(900{ }^{\circ} \mathrm{C}\right)$ to study the effect of different $\mathrm{Al} / \mathrm{Si}$ molar ratio $R$ on composition of samples $\mathrm{S} 2, \mathrm{~S} 3, \mathrm{~S} 4$ and $\mathrm{S} 5$.

Figure 3 shows the XRD patterns of samples S2, S3, $\mathrm{S} 4$ and S5 prepared for $1 \mathrm{~h}$ holding time at $900{ }^{\circ} \mathrm{C}$ with different $R$ values in the raw mixture salts. There exist the diffraction peaks corresponding to mullite, $\mathrm{Si}$ and $\gamma-\mathrm{Al}_{2} \mathrm{O}_{3}$ in sample $\mathrm{S} 2$, indicating that the product is a tri-phase composite consisting of major phase mullite, minor phase $\mathrm{Si}$ and tiny phase $\gamma-\mathrm{Al}_{2} \mathrm{O}_{3}$. However, with the increase of $R$ value, the content of residual $\mathrm{Si}$ in the final product gradually decreases, simultaneously forms a new compound $\mathrm{Al}_{1.7} \mathrm{O}_{2.85} \mathrm{Si}_{0.15}$ (PDF\#290086). When the $\mathrm{Al} / \mathrm{Si}$ molar ratio is up to 3.5 , the peaks ascribed to residual $\mathrm{Si}$ are not observed in sample S3. The diffraction intensity of compound $\mathrm{Al}_{1.7} \mathrm{O}_{2.85} \mathrm{Si}_{0.15}$ increases gradually with $R$ value increasing, demonstrating Al-rich molten salt is benefit for the $\mathrm{Al}_{1.7} \mathrm{O}_{2.85} \mathrm{Si}_{0.15}$ formation.

\subsection{FT-IR analysis}

FT-IR spectra of the samples S2, S3, S4 and S5 are

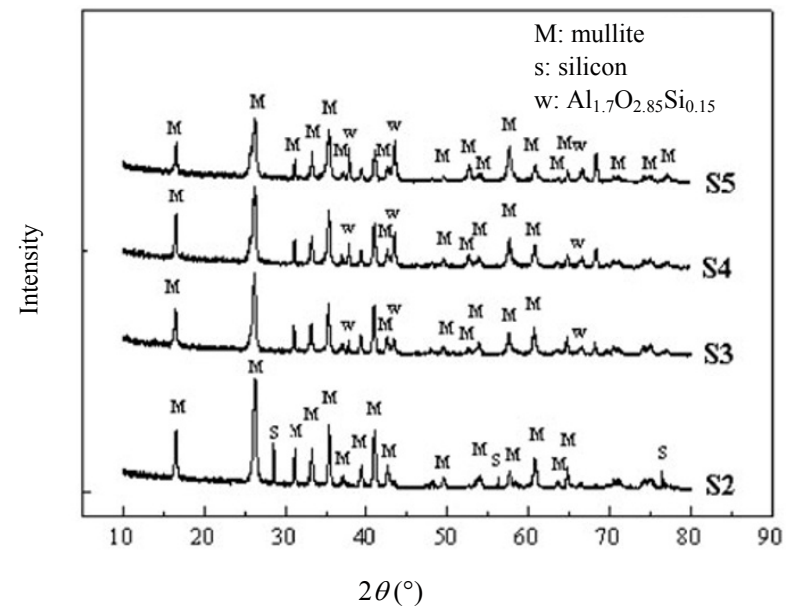

Fig. 3 X-ray diffraction patterns of samples $\mathrm{S} 2, \mathrm{~S} 3$, S4 and S5 prepared at $900{ }^{\circ} \mathrm{C}$ with different $R$ shown in Fig. 4. The absorption peaks of sample S2 at $3426 \mathrm{~cm}^{-1}$ and $1619 \mathrm{~cm}^{-1}$ are assigned to absorbed water from environment $[15,16]$, and that at $1143 \mathrm{~cm}^{-1}$, $838 \mathrm{~cm}^{-1}, 619 \mathrm{~cm}^{-1}$ and $536 \mathrm{~cm}^{-1}$ are assigned to mullite. The absorption peak at $1143 \mathrm{~cm}^{-1}$ is attributed to the $\mathrm{Si}-\mathrm{O}-\mathrm{Si}$ stretching vibration of $\mathrm{SiO}_{4}$, and three absorption peaks at $838 \mathrm{~cm}^{-1}, 619 \mathrm{~cm}^{-1}$ and $536 \mathrm{~cm}^{-1}$ are attributed to the vibration of tetrahedral and octahedral coordination Al-O bonds. The spectra of samples S3, S4 and S5 display that they have similar absorption wavelength compared with sample S2, and the observed frequencies are listed in Table 1. Two absorption bands centring at $1500 \mathrm{~cm}^{-1}$ and $426 \mathrm{~cm}^{-1}$ are observed for the sample S2, which were not reported in any public information. These absorption peaks may be ascribed to the vibration of Al-O-Si of $\mathrm{Al}_{1.7} \mathrm{O}_{2.85} \mathrm{Si}_{0.15}$. Moreover, the intensity of these absorption peaks increases with the $R$ values increasing. Because the $\mathrm{Al} / \mathrm{Si}$ molar ratio of mullite is $3: 1$, and excessive aluminum sulfate will lead to residual $\gamma-\mathrm{Al}_{2} \mathrm{O}_{3}$ remained in the final product, the Al-rich phase $\mathrm{Al}_{1.7} \mathrm{O}_{2.85} \mathrm{Si}_{0.15}$ may be formed in the mixture

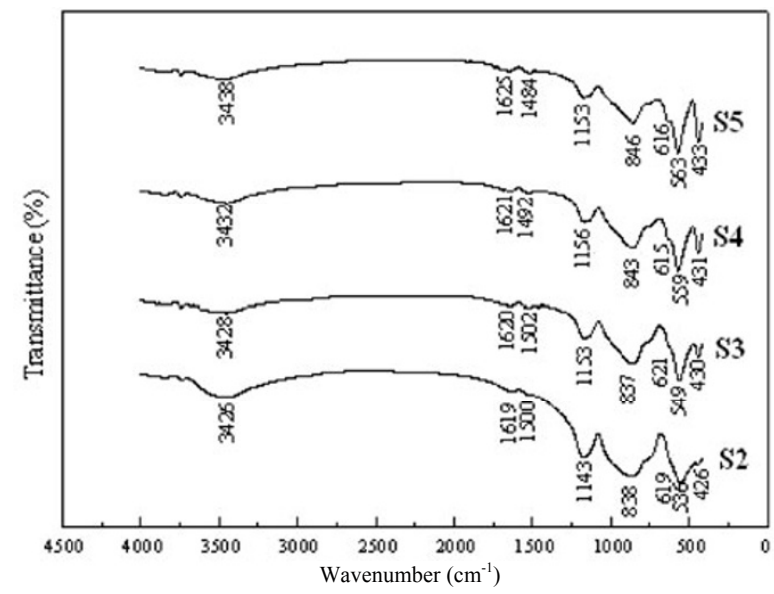

Fig. 4 FT-IR spectra of the samples S2, S3, S4 and $\mathrm{S} 5$ that prepared with different $R$ values.

Table 1 FT-IR frequency assignments of as-prepared samples S2, S3, S4 and S5

\begin{tabular}{|c|c|c|c|c|}
\hline S2 & S3 & S4 & S5 & Assignments \\
\hline $3426 \mathrm{~m} \mathrm{\&} \mathrm{br}$ & $3428 \mathrm{~m} \& \mathrm{br}$ & $3432 \mathrm{~m} \& \mathrm{br}$ & $3438 \mathrm{~m} \& \mathrm{br}$ & $\mathrm{v}(-\mathrm{OH})$ \\
\hline $1619 \mathrm{w}$ & $1620 \mathrm{w}$ & $1621 \mathrm{w}$ & $1625 \mathrm{w}$ & $\mathrm{v}(-\mathrm{OH})$ \\
\hline $1500 \mathrm{vw}$ & $1502 \mathrm{w}$ & $1492 \mathrm{w}$ & $1484 \mathrm{w}$ & $\mathrm{v}(\mathrm{Al}-\mathrm{O}-\mathrm{Si})$ \\
\hline $1143 \mathrm{~s}$ & $1153 \mathrm{~s}$ & $1156 \mathrm{~s}$ & $1153 \mathrm{~s}$ & v (Si-O-Si) \\
\hline 838 s \& br & 837 s \& br & 843 s \& br & 846 s \& br & $\mathrm{v}\left(\mathrm{Al}-\mathrm{O}\right.$ of $\left.\mathrm{AlO}_{4}\right)$ \\
\hline $619 \mathrm{vw}$ & $621 \mathrm{vw}$ & $615 \mathrm{vw}$ & $616 \mathrm{vw}$ & $\mathrm{v}\left(\mathrm{Al}-\mathrm{O}\right.$ of $\left.\mathrm{AlO}_{6}\right)$ \\
\hline $536 \mathrm{~s}$ & $549 \mathrm{~s}$ & $559 \mathrm{~s}$ & $563 \mathrm{~s}$ & $\mathrm{v}\left(\mathrm{Al}-\mathrm{O}\right.$ of $\left.\mathrm{AlO}_{6}\right)$ \\
\hline $426 \mathrm{vw}$ & $430 \mathrm{w}$ & $431 \mathrm{~m}$ & $433 \mathrm{~s}$ & v (Al-O-Si) \\
\hline
\end{tabular}

s: strong; m: medium; w: weak; vw: very weak; br: broad. 
molten salts.

\subsection{SEM analysis}

Figure 5 is representative SEM images of mullite whiskers prepared at $900{ }^{\circ} \mathrm{C}$ for $1 \mathrm{~h}$ with different $R$ values. The images show the needle-like appearances of mullite whiskers clusters with diameters in the range of 100-200 nm and lengths in the range of 2-5 $\mu \mathrm{m}$. And the micrographs also reveal the presence of two kinds of particles: plate-like crystals and clusters of smaller angular crystals [10]. When the $R$ value is 3 (Fig. 4(a)), the product obtained is almost clusters of smaller angular crystals. It can be seen that the amount of plate-like crystals increases with increasing the $R$ value, because excessive aluminum sulfate leads to Al-rich mullite pellets formed in the final product. This is further supported by the absorption intensity increasing in FT-IR spectra and the XRD data.

The corresponding EDS spectrum of the sample S3 shown in Fig. 6(a) indicates that the clusters of mullite tiny-crystal mainly consist of $\mathrm{O}, \mathrm{Al}, \mathrm{Si}$. Moreover, the quantitative analysis shows that their average atomic ratio approximates to $\mathrm{O}: \mathrm{Al}: \mathrm{Si} \approx 13: 6: 2$. While the $\mathrm{Al} / \mathrm{Si}$ molar ratio $(R)$ of raw materials increases, the content of Al-rich mullite pellets improves in the final product. We selected the area of pellets and measured EDS-surface-scanning spectrum of the sample S5 (Fig. 6(b)). It can be seen that $\mathrm{O}(43.2 \%)$ and $\mathrm{Al}(46.24 \%)$ are the main elements, and the content of element $\mathrm{Si}$ is $0.86 \%$. Therefore, the EDS results are consistent with FT-IR and XRD analysis, demonstrating Al-rich molten salts is benefit for plate-like microstructure formation. A small amount of $\mathrm{Na}$ and $\mathrm{S}$ measured in Fig. 6 is originated from $\mathrm{Na}_{2} \mathrm{SO}_{4}$ of raw materials.

\subsection{Formation mechanism of mullite whiskers}

The growth mechanism of mullite whiskers can be explained by oxidation-dissolution process as described in Fig. 7. Firstly, Si powders contacted with molten salts $\left(\mathrm{Al}_{2}\left(\mathrm{SO}_{4}\right)_{3}\right.$ and $\left.\mathrm{Na}_{2} \mathrm{SO}_{4}\right)$ were formed in the interface of solid and liquid, and free Al-cations formed in the liquid before decomposition of $\mathrm{Al}_{2}\left(\mathrm{SO}_{4}\right)_{3}$, which transformed to amorphous $\gamma-\mathrm{Al}_{2} \mathrm{O}_{3}$ above $700{ }^{\circ} \mathrm{C}$ according to the reaction (1). Subsequently, due to the strong oxidation of $\mathrm{SO}_{3}$, the $\mathrm{SiO}_{2}$ coating was formed through the reaction (2) and covered on the surface of $\mathrm{Si}$ powders. Then, the new formed $\mathrm{SiO}_{2}$ coating can be etched by molten salts according to reaction (3) and mullite nuclei were formed in this
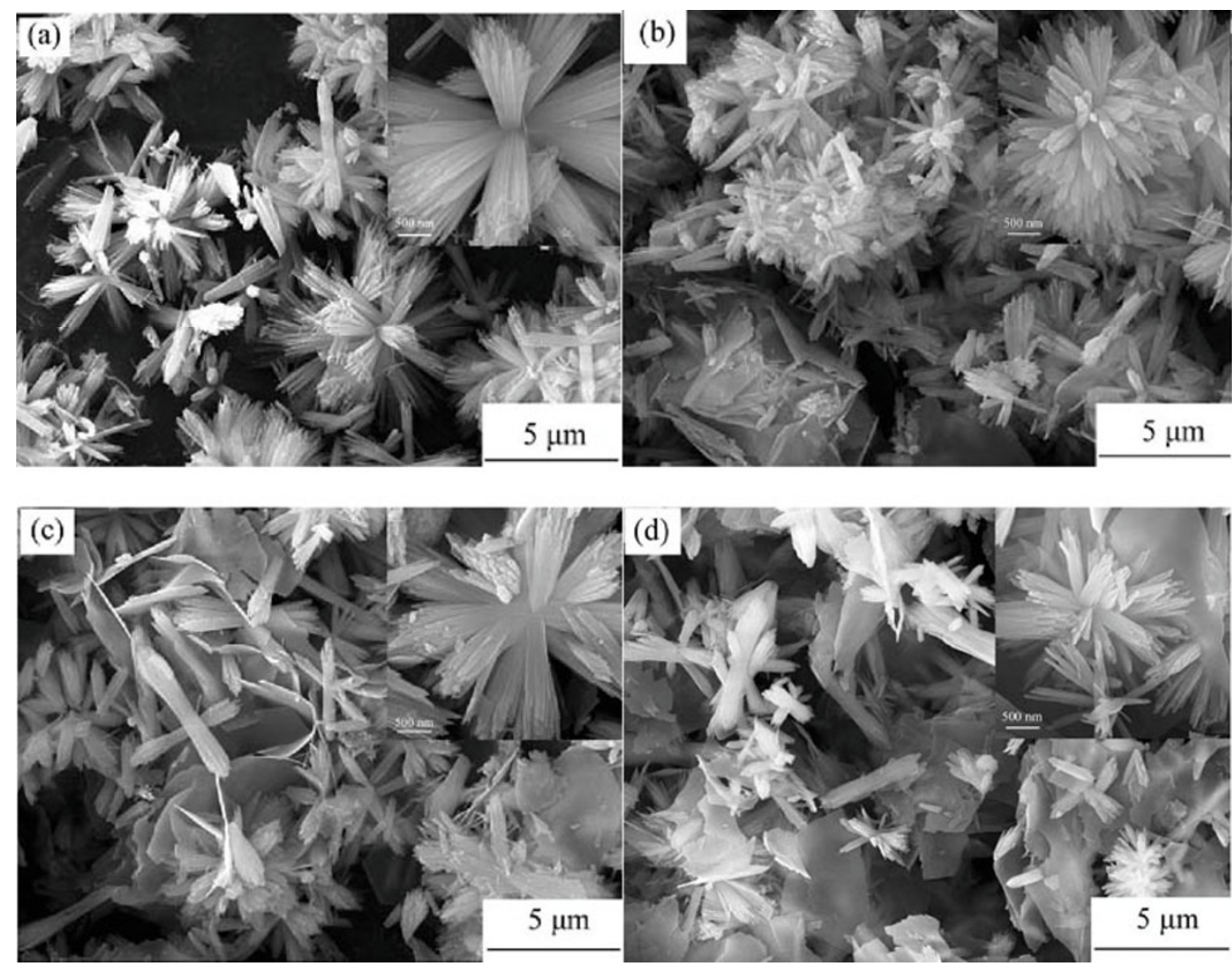

Fig. 5 SEM micrographs of samples S2 (a), S3 (b), S4 (c) and S5 (d) prepared at $900{ }^{\circ} \mathrm{C}$ for $1 \mathrm{~h}$. 

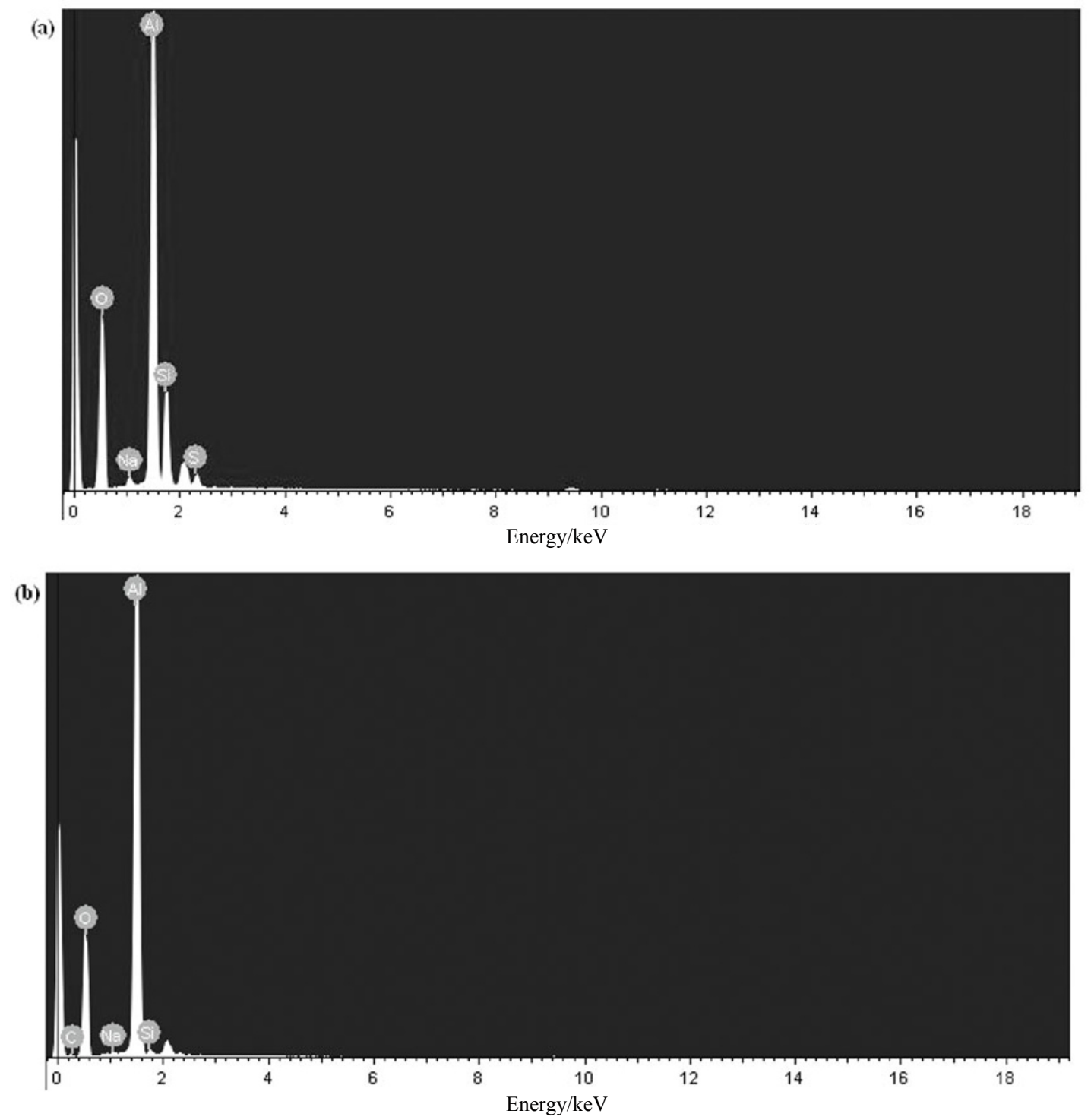

Fig. 6 EDS spectrum of samples S3 (a) and S5 (b).

process. At the same time, free $\mathrm{Si}$ substrate was exposed to molten salts system and the oxidation reaction would follow. By repeating this oxidation-dissolution cycle, the active $\mathrm{Si}$ has been etched completely and the inert mullite whiskers has been grown continuously. This repeated oxidationdissolution mechanism is different from the commonly accepted mechanism of mullite whiskers formation [13], raw material Si powders could be oxidized by $\mathrm{SO}_{3}$ which originated from the decomposition of $\mathrm{Al}_{2}\left(\mathrm{SO}_{4}\right)_{3}$. Thus, mullite nuclei form in the mixture molten salts and mullite whiskers could grow continuously depending on oxidation-dissolution cycle.

$$
\begin{aligned}
\mathrm{Al}_{2}\left(\mathrm{SO}_{4}\right)_{3} & \longrightarrow \gamma-\mathrm{Al}_{2} \mathrm{O}_{3}+3 \mathrm{SO}_{3} \\
\mathrm{Si}+2 \mathrm{SO}_{3} & \longrightarrow \mathrm{SiO}_{2}+2 \mathrm{SO}_{2} \\
3 \gamma-\mathrm{Al}_{2} \mathrm{O}_{3}+2 \mathrm{SiO}_{2} & \longrightarrow 3 \mathrm{Al}_{2} \mathrm{O}_{3} \cdot 2 \mathrm{SiO}_{2} \text { (mullite) }
\end{aligned}
$$

From thermodynamic point of view, one reaction could be estimated qualitatively according to the change free energy $(\Delta G)$ of this reaction. Thus, we calculated the effect of temperature on free energy change of reactions (1), (2) and (3), which are shown in Fig. 8. The data of $G$ are obtained from Reference [17]. As far as chemical equilibrium is concerned, the smaller the value of $\Delta G$, the larger the equilibrium constant $k$ is, and the more the products are when equilibrium state is attained. Therefore, the reaction (1) can not process in the lower temperature range $(\Delta G>$ $0)$, the reaction would start extremely vigorous when the temperature was reaching at $1023 \mathrm{~K}(\Delta G<0)$. It is found that the free energy change of reactions (2) and (3) are negative in the whole temperature range, which indicated that reactions are spontaneous. From the 


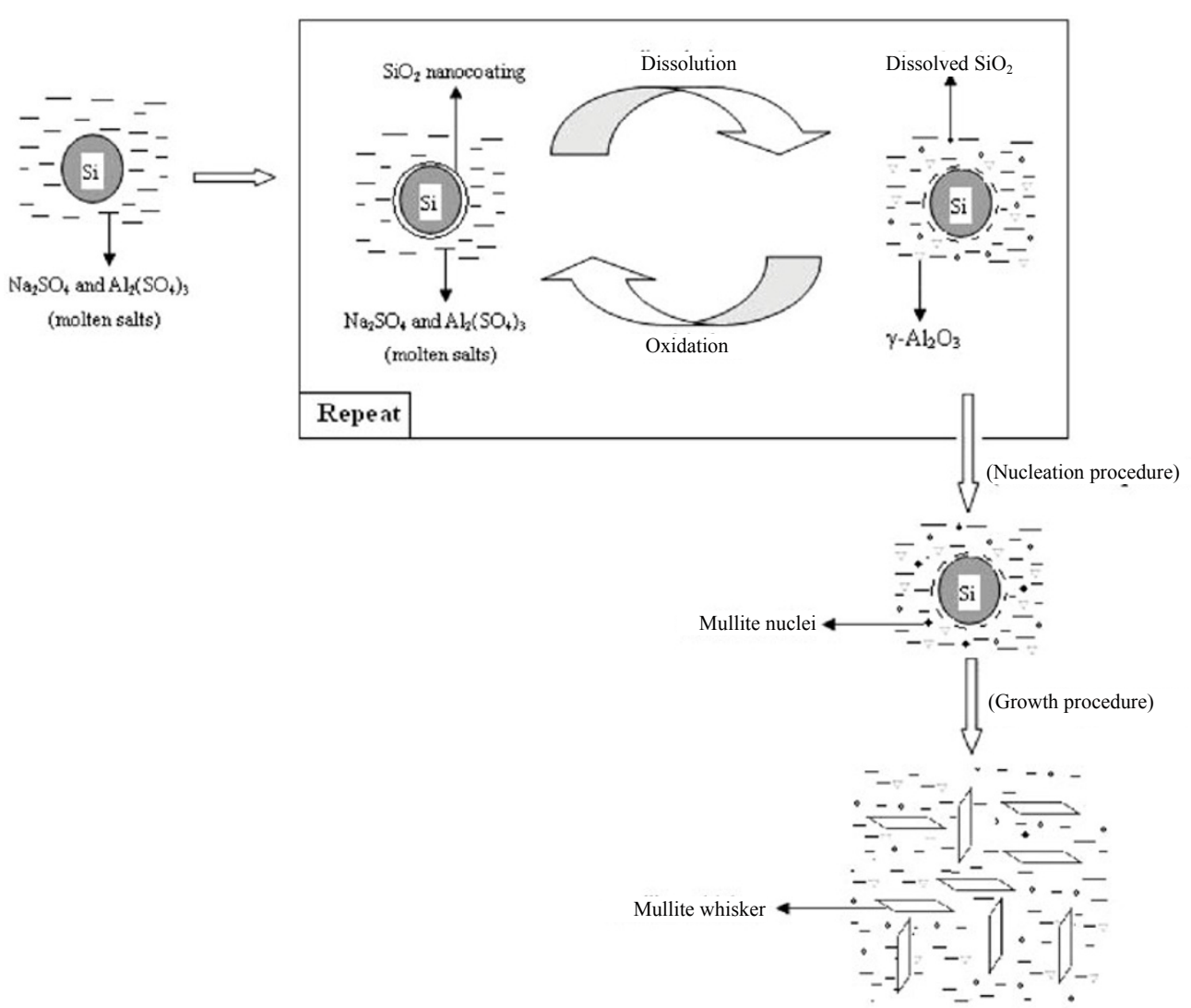

Fig. 7 Schematic illustration of growth process of mullite whiskers.

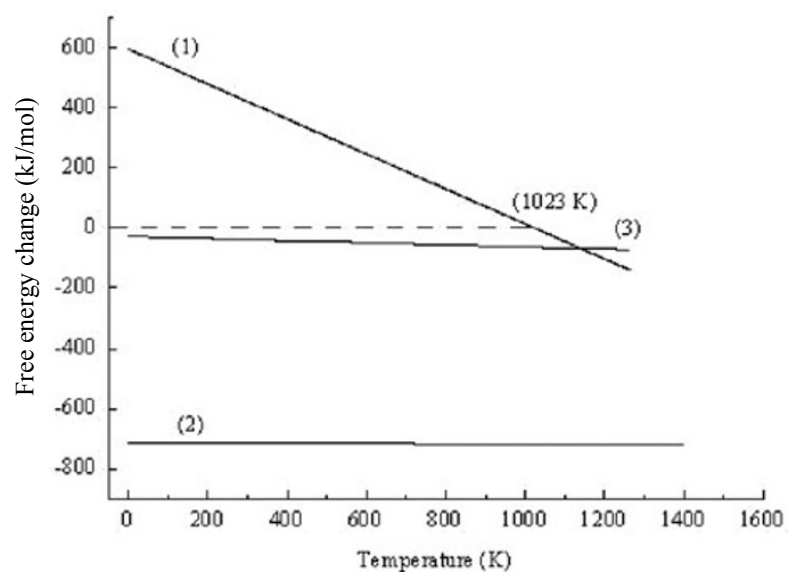

Fig. 8 Change of free energy $\Delta G$ for reactions (1), (2) and (3) depending on temperature.

temperature range of $0-1400 \mathrm{~K}$, mullite whiskers form and grow controlled by reaction (1). This implies that mullite phase may spontaneously form once the temperature of the molten salts reaches the decomposition temperature of aluminum sulfate.

The mixture molten salts contact with solid-state $\mathrm{Si}$ powders, which is converted in a short period under these conditions especially when they are liquid mixed in a molecular level, which will shorten the diffusion paths, so that the reaction kinetics need not be considerated. This principle is applied in our investigations and the results are discussed in this paper.

\section{Conclusions}

Mullite whiskers were prepared from Si powders using molten $\mathrm{Al}_{2}\left(\mathrm{SO}_{4}\right)_{3}-\mathrm{Na}_{2} \mathrm{SO}_{4}$ salts method. XRD, FT-IR, SEM and EDS studies showed that Al-rich mullite pellets and clusters of tiny mullite crystals were formed in the final product. In addition, the content of Al-rich mullite pellets increases with the $R$ of raw mixture salts increasing. A new oxidation-dissolution mechanism was proposed to explain mullite whiskers growth. Thermodynamic calculation indicated that mullite phase may be spontaneously formed as the temperature reached the decomposition temperature of aluminum sulfate (1023 K).

\section{Acknowledgement}

This work was supported by the Fundamental Research 
Funds for the Central Universities (CHD2009JC143) and the Open Fund of State Key Laboratory for Mechanical Behavior of Materials (201011004).

\section{References}

[1] Zhang YB, Ding YP, Gao JQ, et al. Mullite fibres prepared by sol-gel method using polyvinyl butyral. J Eur Ceram Soc 2009, 29: 1101-1107.

[2] Bagchi B, Das S, Bhattacharya A, et al. Nanocrystalline mullite synthesis at a low temperature: Effect of copper ions. $J$ Am Ceram Soc 2009, 92: 748-751.

[3] Kong LB, Zhang TS, Ma J, et al. Mullitization behavior and microstructural development of $\mathrm{B}_{2} \mathrm{O}_{3}-\mathrm{Al}_{2} \mathrm{O}_{3}-\mathrm{SiO}_{2}$ mixtures activated by high-energy ball milling. Solid Sate Sci 2009, 11: 1333-1342.

[4] Zhang TS, Kong LB, Du ZH, et al. In situ interlocking structure in gel-derived mullite matrix induced by mechanoactivated commercial mullite powders. Scripta Mater 2010, 63: 1132-1135.

[5] Zhang TS, Kong LB, Du ZH, et al. Tailoring the microstructure of mechanoactivated $\mathrm{Al}_{2} \mathrm{O}_{3}$ and $\mathrm{SiO}_{2}$ mixtures with $\mathrm{TiO}_{2}$ addition. $J$ Alloys Compd 2010, 506: 777-783.

[6] Roy B, Fuierer PA. Molten salt synthesis of Bi-4(V0.85Co0.15)(2)O11-delta (BICOVOX) ceramic powders. J Am Ceram Soc 2009, 92: 520-523.

[7] Li JF, Lin H, Li JB, et al. Effects of different potassium salts on the formation of mullite as the only crystal phase in kaolinite. J Eur Ceram Soc 2009, 29: 2929-2936.
[8] Park YM, Yang TY, Yoon SY, et al. Mullite whiskers derived from coal fly ash. Mater Sci Eng A 2007, 454-455: 518-522.

[9] Zhang PY, Liu JC, Du HY, et al. Molten salt synthesis of mullite whiskers from various alumina precursors. J Alloys Compd 2010, 491: 447-451.

[10] Ouatib RE, Guillemet S, Durand B, et al. Reactivity of aluminum sulfate and silica in molten alkali-metal sulfates in order to prepare mullite. $J$ Eur Ceram Soc 2005, 25: 73-80.

[11] Kong LB, Gan YB, Ma J, et al. Mullite phase fromation and reaction sequences with the presence of pentoxides. J Alloys Compd 2003, 351: 264-272.

[12] Kim BM, Cho YK, Yoon SY, et al. Mullite whiskers derived from kaokin. Ceram Int 2009, 35: 579-583.

[13] Zhang PY, Liu JC, Du HY, et al. Influence of silica sources on morphology of mullite whiskers in $\mathrm{Na}_{2} \mathrm{SO}_{4}$ flux. $J$ Alloys Compd 2009, 484: 580-584.

[14] Levin EM, Mcmurdie HF. Phase diagrams for ceramists 1975 supplement. Am Ceram Soc OH, Westerville, 1975: 1318-1318.

[15] Liu K, Feng Q, Yang YX, et al. Preparation and characterization of amorphous silica nanowires from natural chrysotile. J Non-Cryst Solids 2007, 353: 1534-1539.

[16] Lavat AE, Grasselli MC, Tasca JE. Phase changes of ceramic whiteware slip-casting bodies studied by XRD and FTIR. Ceram Int 2007, 33: 1111-1117.

[17] Barin I. Thermochemical Data of Pure Substances. Weinheim: VCH Verlagsgesellschaft, 1989. 